\title{
Rare Neurologic Diseases and Neurological Sciences: a report for the celebration of the 2020 Rare Diseases Day
}

\author{
Antonio Federico ${ }^{1}$ \\ Published online: 15 February 2020 \\ (C) Fondazione Società Italiana di Neurologia 2020
}

\section{Introduction}

In the recent years, a great interest has been given to rare diseases, that are over 6000 different pathological conditions, affecting more than 300 million people around the world, more than $70 \%$ with genetic pathogenesis, and more than $50 \%$ with neurologic or muscle involvement. For years, research projects have been developed, discovering many genes related to the pathogenesis of many disorders and also new therapies.

In the same time, in order to promote the better knowledge of these conditions, many actions have been developed, able to improve the information between doctors, families, and also institutions.

One of these is the Rare Diseases Day, that is celebrating every year, on the last day of February (this year on the February 29th).

Rare Disease Day is a great example of how progress continues to be made in this area. Beginning in 2008, which events only in 18 countries, Rare Disease Day has taken place every year with events being held in over 100 countries in 2019.

Neurological Sciences, as done on the past year, participates to the Rare Diseases Day activities promoting the knowledge and the attention on rare neurologic disorders, reporting the main articles published on the journal in 2019 related to Rare Neurologic Diseases.

We hope that this action may help our readers to be more familiar with rare neurologic diseases, facilitating their early diagnosis and promoting new researches on therapies.

In 2019, our journal published 61 articles related to rare neurologic diseases out of a total of more than 450 articles, the majority (34) referring the clinical aspects of many different diseases, 10 amyotrophic lateral sclerosis, 12 new genetic

Antonio Federico

antonio.federico@unisi.it

1 Department Medicine, Surgery an Neurosciences, Medical School, University of Siena, Viale Bracci 2, 53100 Siena, Italy mutations, 8 pathogenetic aspects, 5 recommendations, guidelines, and reviews, and 2 therapies.

\section{Clinical aspects of Rare Neurologic Diseases}

The heterogeneity of brain FDG-PET metabolic patterns in patients with $\mathrm{C} 9$ orf72 mutation was described by Castelnovo et al. [1]. A neurobehavioral phenotype of familial Creutzfeldt-Jakob disease lead to Giovagnoli et al. [2] to discuss an impairment of theory of mind; a fronto-temporal type of dementia was reported associated to Langerhans cell histiocytosis by Garg et al. [3]. Body composition analysis in patients with myotonic dystrophy types 1 and 2 was described by Peric et al. [4]; a case report of cerebellar ataxia associated with anti-glutamic acid decarboxylase antibodies was reported by Villa et al. [5]. Late-onset and fast progressive neuropathy and cardiomyopathy was associated to Val32Ala transthyretin gene mutation (Cazzato et al.) [6]. A rare cause of Horner's syndrome, cervicothoracic spinal root cysts, was described by Karti et al. [7]. Clinical, radiological features, and surgical strategies for $23 \mathrm{NF} 1$ patients with intraorbital meningoencephalocele were reported by Niu et al. [8], and Santoro et al. [9] in a child with neurofibromatosis type 2 and unilateral moyamoya discussed on further evidence of cerebral vasculopathy in NF2 and SCN11A variant as possible pain generator in sensory axonal neuropathy (Ginanneschi et al.) [10]. Desensitization of two young patients with infantile-onset Pompe disease and severe reactions to alglucosidase alfa was described by Gragnaniello et al. [11]; an overview on degenerative and acquired sporadic adult onset ataxia was reported by Lieto et al. [12] and by Teive et al. [13]. Lieto et al. [14] also reported a longitudinal study of a cohort of MSA-C patients in South Italy discussing their survival and clinical features. A rare case of pure sensitive Parsonage-Turner syndrome was described by Pessa et al. [15]. Nesti et al. [16] reported a complex multisystem phenotype associated with the mitochondrial DNA m.5522G $>$ A 
mutation. Escorcio-Bezerra et al. [17] focused the attention on tonic pupils as an unusual autonomic involvement in chronic inflammatory demyelinating polyneuropathy (CIDP), while Kobayashi et al. [18]) suggested that ischemic stroke was associated to sarcoidosis for the presence of arterial wall enhancement. Qin [19] showed association of HIF1A and Parkinson's disease in a Han Chinese population by molecular inversion probe analysis, and Yin et al. [20] by a meta-analysis reported the relationship with BDNF Val66Met polymorphism and cognitive impairment in Parkinson's disease. Basal ganglia calcifications (Fahr's syndrome) and related condition were discussed by Donzuso et al. [21]. Malaquias et al. [22] described GNAO1 mutation presenting as dyskinetic cerebral palsy. Liu et al. [23] reported a case of recurrent vomiting extending the spectrum of neuronal intranuclear inclusion disease; carrier frequency of spinal muscular atrophy in Thailand was described by Dejsuphong et al. [24], and Savcun Demirci [25] described the effect of taping on scapular kinematics of patients with facioscapulohumeral muscular dystrophy. An atypical clinical manifestations of Miller Fisher syndrome was reported by Jung [26].

\section{Amyotrophic lateral sclerosis}

Amyotrophic lateral sclerosis (ALS) is the most frequent rare neurologic diseases. This is reflected also in the article published in 2019 in our journal and reported in Table 1.

Table 1 Articles on ALS published in Neurological Journal in 2019

Dardiotis et al. [27], ERCC6L2 rs591486 polymorphism and risk for amyotrophic lateral sclerosis in Greek population.

Luo et al. [28], Efficacy and safety of edaravone in treatment of amyotrophic lateral sclerosis - a systematic review and meta-analysis

Sivaramakrishnan et al. [29], Recumbent stepping aerobic exercise in amyotrophic lateral sclerosis: a pilot study

Amin Lari et al. [30], A review of electrophysiological studies of lower motor neuron involvement in amyotrophic lateral sclerosis

Hancevic et al. [31], Attenuation of ALS progression during pregnancylessons to be learned or just a coincidence?

Verde et al. [32], PON1 is a disease modifier gene in amyotrophic lateral sclerosis: association of the Q192R polymorphism with bulbar onset and reduced survival

Sprovieri et al. [33], A novel S379A TARDBP mutation associated to late-onset sporadic ALS

Yang et al. [34], UNC13A variant rs 12608932 is associated with increased risk of amyotrophic lateral sclerosis and reduced patient survival: a meta-analysis

Park et al. [35], Under-recognized primary spontaneous pneumothorax in ALS: a multicenter retrospective study

Corrado et al. [36], Analysis of the GCG repeat length in NIPA1 gene in C9orf72-mediated ALS in a large Italian ALS cohort

Santus et al. [37], Orthostatic tremor and behavioral frontotemporal dementia: a case report with 7 years of follow-up.
Table 2 Articles with new genetic mutations of Rare Neurologic Diseases published in 2019 in Neurological Sciences

Koh et al. [38], Decreasing 123I-ioflupane SPECT accumulation and 123 I-MIBG myocardial scintigraphy uptake in a patient with a novel homozygous mutation in the ZFYVE26 gene

Abdulkareem et al. [39], A novel homozygous nonsense mutation in CCDC88A gene cause PEHO-like syndrome in consanguineous Saudi family

Zhang et al. [40], A novel missense mutation in the ABCD1 gene of a Chinese boy diagnosed with X-linked adrenoleukodystrophy: case report

Genc et al. [41], Methylation of cation-chloride cotransporters NKCC1 and $\mathrm{KCC} 2$ in patients with juvenile myoclonic epilepsy

Kaur et al. [42], L-type calcium channel blockers and a symptom complex mimicking de Melo-Souza's syndrome

Oliva [43], A novel SLC20A2 gene mutation causing primary familial brain calcification in an Ukrainian patient

Du [44], A novel mutation in the CSF1R gene causes hereditary diffuse leukoencephalopathy with axonal spheroids

Liu et al. [45], G327E mutation in SCN9A gene causes idiopathic focal epilepsy with Rolandic spikes: a case report of twin sisters

Catania et al. [46], DNMT1-complex disorder caused by a novel mutation associated with an overlapping phenotype of autosomal-dominant cerebellar ataxia, deafness, and narcolepsy (ADCA-DN) and hereditary sensory neuropathy with dementia and hearing loss (HSN1E)

Ferrante et al. [47], Identification of a novel NOTCH3 mutation in an Italian family affected by a mild form of CADASIL

\section{New genetic mutations}

Since the majority of Rare Neurologic Diseases has a genetic cause, the research in the discovering of new mutation on the basis of the different phenotypic presentations has a big interest. Article describing new genetic mutations published in Neurologic Sciences are reported in Table 2.

\section{Pathogenetic mechanisms}

Rare Neurologic Diseases are also useful for studying the different pathogenetic mechanisms underlying the symptoms. These investigations have also been published on Neurologic Sciences in 2019 and reported in Table 3.

Table 3 Articles on pathogenetic mechanisms of Rare Neurologic Diseases published in Neurologic Sciences in 2019

$\mathrm{Wu}$ [48], Inflammatory cytokines expression in Wilson's disease

Smolinski et al. [49], Brain volume is related to neurological impairment and to copper overload in Wilson's disease

Rucco et al. [50], Mutations in the SPAST gene causing hereditary spastic paraplegia are related to global topological alterations in brain functional networks

Ginanneschi et al. [10], SCN11A variant as possible pain generator in sensory axonal neuropathy

Wang et al. [51], Abnormal nuclear aggregation and myotube degeneration in myotonic dystrophy type 1

Alpaydin-Baslo et al. [52], Is Hirayama a Gq1b disease?

Bohi et al. [53], Knuckle pigmentation, peripheral neuropathy, madness and abnormal movement: is it B12 deficiency?

Pianese et al. [54], Maternal germline mosaicism in Fabry disease 
Table 4 Miscellanea articles on Rare Neurologic Diseases published in Neurologic Sciences in 2019



Other findings related to Rare Neurologic Diseases are reported in Table 4.

\section{Conclusions}

All our data confirm the strong interest of the neurologic community in Rare Neurologic Diseases, representing an important area of scientific interest and innovation. With this editorial, we want to contribute to focus the attention on the important role of Rare Neurologic Diseases in the Neuroscience research and improve the knowledge of this important but still neglected area of Neurology.

Acknowledgments We thank Giovanna Castelli for her precious assistance in the reference collecting and editing.

\section{Compliance with Ethical Standards}

Conflict of interest None.

\section{References}

1. Castelnovo V, Caminiti SP, Riva N, Magnani G, Silani V, Perani D (2019) Heterogeneous brain FDG-PET metabolic patterns in patients with C9orf72 mutation. Neurol Sci 40(3):515-521

2. Giovagnoli AR, Tallarita G, Parente A, Del Sole A, Di Fede G (2019) A new neurobehavioral phenotype of familial CreutzfeldtJakob disease: impaired theory of mind. Neurol Sci 40(5):10731075

3. Garg D, Pedapati R, Nakra T, Singh RK, Prabhakar A, Dash D, Bhatia R, Tripathi M (2019) Langerhans cell histiocytosis presenting as a rapidly evolving fronto-temporal syndrome. Neurol Sci 40(5):1055-1058
4. Peric S, Bozovic I, Nisic T, Banovic M, Vujnic M, Svabic T, Pesovic J, Brankovic M, Basta I, Jankovic M, Savic-Pavicevic D, Rakocevic-Stojanovic V (2019) Body composition analysis in patients with myotonic dystrophy types 1 and 2. Neurol Sci 40(5): 1035-1040

5. Villa SM, Rufa A, Malandrini A, Cerase A, Rosini F, Arrigucci U, Federico A (2019) Cerebellar ataxia associated with anti-glutamic acid decarboxylase antibodies: a case report. Neurol Sci 40(6): 1303-1306

6. Cazzato D, Dalla Bella E, Saveri P, Taroni F, Marucci G, Lauria G (2019) Late-onset and fast progressive neuropathy and cardiomyopathy in Val32Ala transthyretin gene mutation. Neurol Sci 40(6): $1267-1269$

7. Karti DT, Karti O, Celebisoy N (2019) A rare cause of Horner's syndrome: cervicothoracic spinal root cysts. Neurol Sci 40(6): $1311-1314$

8. Niu J, Wang J, Wang D, He X, Li Z, Li X, Su F, Jia W (2019) Clinical, radiological features and surgical strategies for $23 \mathrm{NF} 1$ patients with intraorbital meningoencephalocele. Neurol Sci 40(6):1217-1225

9. Santoro C, Palladino F, Bernardo P, Cinalli G, Mirone G, Giugliano T, Piluso G, Perrotta S (2019) Report on a child with neurofibromatosis type 2 and unilateral moyamoya: further evidence of cerebral vasculopathy in NF2. Neurol Sci 40(7):1475-1476

10. Ginanneschi F, Rubegni A, Moro F, Volpi N, Santorelli FM, Rossi A (2019) SCN11A variant as possible pain generator in sensory axonal neuropathy. Neurol Sci 40(6):1295-1297

11. Gragnaniello V, Fecarotta S, Pecoraro A, Tarallo A, Catzola A, Spadaro G, Parenti G, Della Casa R (2019) Desensitization of two young patients with infantile-onset Pompe disease and severe reactions to alglucosidase alfa. Neurol Sci 40(7):1453-1455

12. Lieto M, Roca A, Santorelli FM, Fico T, De Michele G, Bellofatto M, Saccà F, De Michele G, Filla A (2019) Degenerative and acquired sporadic adult onset ataxia. Neurol Sci 40(7):1335-1342

13. Teive HAG, Camargo CHF, Munhoz RP (2019) Sporadic adultonset spinocerebellar ataxias : reply: degenerative and acquired sporadic adult-onset ataxiahttps. Neurol Sci 40(12):2657-2658. https://doi.org/10.1007/s10072-019-03856-w

14. Lieto $M$, Roca $A$, Bruzzese $D$, Antenora $A$, Alfieri $G$, Saccà $F$, Bellofatto M, Bilo L, Barbato S, De Michele G, Filla A (2019) Longitudinal study of a cohort of MSA-C patients in South Italy: survival and clinical features. Neurol Sci 40(10):2105-2109

15. Pessa ME, Verriello L, Valente M, Gigli GL (2019) A rare case of pure sensitive parsonage-turner syndrome. Neurol Sci 40(7):1499 1501

16. Nesti C, Rubegni A, Tolomeo D, Baldacci J, Cassandrini D, D'Amore F, Santorelli FM (2019) Complex multisystem phenotype associated with the mitochondrial DNA m.5522G $>$ A mutation. Neurol Sci 40(8):1705-1708

17. Escorcio-Bezerra ML, Manzano GM, Bichuetti DB, Nunes KF, Correa DSA, Oliveira ASB, Baeta AM (2019) Tonic pupils: an unusual autonomic involvement in chronic inflammatory demyelinating polyneuropathy (CIDP). Neurol Sci 40(8):1725-1727

18. Kobayashi M (2019) Ischemic stroke due to sarcoidosis: the arterial wall enhancement on magnetic resonance imaging. Neurol Sci 40(9):1967-1970

19. Qin L, Shu L, Zhong J, Pan H, Guo J, Sun Q, Yan X, Tang B, Xu Q (2019) Association of HIF1A and parkinson's disease in a Han Chinese population demonstrated by molecular inversion probe analysis. Neurol Sci 40(9):1927-1931

20. Yin Y, Su X, Pan L, Li C (2019) BDNF Val66Met polymorphism and cognitive impairment in Parkinson's disease-a meta-analysis. Neurol Sci 40(9):1901-1907

21. Donzuso G, Mostile G, Nicoletti A, Zappia M (2019) Basal ganglia calcifications (Fahr's syndrome): related conditions and clinical features. Neurol Sci 40(11):2251-2263 
22. Malaquias MJ, Fineza I, Loureiro L, Cardoso L, Alonso I, Magalhães M (2019) GNAO1 mutation presenting as dyskinetic cerebral palsy. Neurol Sci 40(10):2213-2216

23. Liu X, Liu X, Du Y, Lin Y, Li C, Liu C, Lu L (2019) A case of recurrent vomiting:extending the spectrum of neuronal intranuclear inclusion disease. Neurol Sci 40(12):2661-2664

24. Dejsuphong D, Taweewongsounton A, Khemthong P, Chitphuk S, Stitchantrakul W, Sritara P, Tunteeratum A, Sura T (2019) Carrier frequency of spinal muscular atrophy in Thailand. Neurol Sci 40(8): $1729-1732$

25. Savcun Demirci C, Onursal Kılınç Ö, Yıldız Tİ, Ayvat E, Ayvat F, Turgut E, Düzgün İ, Aksu Yıldırım S, Kılınç M (2019) Effect of taping on scapular kinematics of patients with facioscapulohumeral muscular dystrophy. Neurol Sci 40(8):1583-1588

26. Jung JH, Oh EH, Shin JH, Kim DS, Choi SY, Choi KD, Choi JH (2019) Atypical clinical manifestations of miller fisher syndrome. Neurol Sci 40(1):67-73

27. Dardiotis E, Karampinis E, Siokas V, Aloizou AM, Rikos D, Ralli S, Papadimitriou D, Bogdanos DP, Hadjigeorgiou GM (2019) ERCC6L2 rs591486 polymorphism and risk for amyotrophic lateral sclerosis in Greek population. Neurol Sci 40(6):1237-1244

28. Luo L, Song Z, Li X, Huiwang ZY, Qinwang M, He J (2019) Efficacy and safety of edaravone in treatment of amyotrophic lateral sclerosis-a systematic review and meta-analysis. Neurol Sci 40(2): 235-241

29. Sivaramakrishnan A, Madhavan S (2019) Recumbent stepping aerobic exercise in amyotrophic lateral sclerosis: a pilot study. Neurol Sci 40(5):971-978

30. Amin Lari A, Ghavanini AA, Bokaee HR (2019) A review of electrophysiological studies of lower motor neuron involvement in amyotrophic lateral sclerosis. Neurol Sci 40(6):1125-1136

31. Hancevic M, Bilic H, Sitas B, Pavlisa G, Borovecki F, Munitic I, Bilic E (2019) Attenuation of ALS progression during pregnancylessons to be learned or just a coincidence? Neurol Sci 40(6):12751278

32. Verde F, Tiloca C, Morelli C, Doretti A, Poletti B, Maderna L, Messina S, Gentilini D, Fogh I, Ratti A, Silani V, Ticozzi N (2019) PON1 is a disease modifier gene in amyotrophic lateral sclerosis: association of the Q192R polymorphism with bulbar onset and reduced survival. Neurol Sci 40(7):1469-1473

33. Sprovieri T, Ungaro C, Perrone B, Naimo GD, Spataro R, Cavallaro S, La Bella V, Conforti FL (2019) A novel S379A TARDBP mutation associated to late-onset sporadic ALS. Neurol Sci 40(10): 2111-2118

34. Yang B, Jiang H, Wang F, Li S, Wu C, Bao J, Zhu Y, Xu Z, Liu B, Ren H, Yang X (2019) UNC13A variant rs12608932 is associated with increased risk of amyotrophic lateral sclerosis and reduced patient survival: a meta-analysis. Neurol Sci 40(11):2293-2302

35. Park JS, Do YW, Park JM, Seok HY, Park D (2019) Underrecognized primary spontaneous pneumothorax in ALS: a multicenter retrospective study. Neurol Sci 40(12):2509-2514

36. Corrado L, Brunetti M, Di Pierro A, Barberis M, Croce R, Bersano E, De Marchi F, Zuccalà M, Barizzone N, Calvo A, Moglia C, Mazzini L, Chiò A, D'Alfonso S (2019) Analysis of the GCG repeat length in NIPA1 gene in C9orf72-mediated ALS in a large Italian ALS cohort. Neurol Sci 40(12):2537-2540

37. Santus G, Faletti S, Grandis D (2019) Orthostatic tremor and behavioral frontotemporal dementia: a case report with 7 years of follow-up. Neurol Sci 40(11):2415-2417

38. Koh K, Tsuchiya M, Nagasaka T, Shindo K, Takiyama Y (2019) Decreasing (123)I-ioflupane SPECT accumulation and (123)IMIBG myocardial scintigraphy uptake in a patient with a novel homozygous mutation in the ZFYVE26 gene. Neurol Sci 40(2): 429-431

39. Abdulkareem AA, Abulnaja KO, Jan MM, Karim S, Rasool M, Ansari SA, Chaudhari AG, Al-Qahtani MH, Naseer MI (2019) A novel homozygous nonsense mutation in CCDC88A gene cause PEHO-like syndrome in consanguineous Saudi family. Neurol Sci 40(2):299-303

40. Zhang M, Shi S, Zhang H, Liu L, Wu L, Xiao B, Liu W (2019) A novel missense mutation in the ABCD1 gene of a Chinese boy diagnosed with $\mathrm{X}$-linked adrenoleukodystrophy: case report. Neurol Sci 40(5):1093

41. Genç F, Kara M, Ünal Y, Uygur Küçükseymen E, Biçer Gömceli Y, Kaynar T, Tosun K, Kutlu G (2019) Methylation of cation-chloride cotransporters $\mathrm{NKCC} 1$ and $\mathrm{KCC} 2$ in patients with juvenile myoclonic epilepsy. Neurol Sci 40(5):1007-1013

42. Kaur U, Das P, Gambhir IS, Chakrabarti SS (2019) L-type calcium channel blockers and a symptom complex mimicking de MeloSouza's syndrome. Neurol Sci 40(5):1077-1080

43. Oliva M, Capaldo G, D'Amico A, Colavito D, Elefante A, Straccia G, Ugga L, Puoti G (2019) A novel SLC20A2 gene mutation causing primary familial brain calcification in an Ukrainian patient. Neurol Sci 40(6):1283-1285

44. Du Q, Chen H, Shi Z, Zhang Y, Wang J, Zhou H (2019) A novel mutation in the CSF1R gene causes hereditary diffuse leukoencephalopathy with axonal spheroids. Neurol Sci 40(6): $1287-1290$

45. Liu Z, Ye X, Qiao P, Luo W, Wu Y, He Y, Gao P (2019) G327E mutation in SCN9A gene causes idiopathic focal epilepsy with Rolandic spikes: a case report of twin sisters. Neurol Sci 40(7): $1457-1460$

46. Catania A, Peverelli L, Tabano S, Ghezzi D, Lamperti C (2019) DNMT1-complex disorder caused by a novel mutation associated with an overlapping phenotype of autosomal-dominant cerebellar ataxia, deafness, and narcolepsy (ADCA-DN) and hereditary sensory neuropathy with dementia and hearing loss (HSN1E). Neurol Sci 40(9): 1963-1966

47. Ferrante E, Mosca L, Erminio C, Penco S, Cavallari U (2019) Identification of a novel NOTCH3 mutation in an Italian family affected by a mild form of CADASIL. Neurol Sci 40(8):1751-1753

48. Wu P, Dong J, Cheng N, Yang R, Han Y, Han Y (2019) Inflammatory cytokines expression in Wilson's disease. Neurol Sci 40(5):1059-1066

49. Smolinski L, Litwin T, Redzia-Ogrodnik B, Dziezyc K, Kurkowska-Jastrzebska I, Czlonkowska A (2019) Brain volume is related to neurological impairment and to copper overload in Wilson's disease. Neurol Sci 40(10):2089-2095

50. Rucco R, Liparoti M, Jacini F, Baselice F, Antenora A, De Michele G, Criscuolo C, Vettoliere A, Mandolesi L, Sorrentino G, Sorrentino P (2019) Mutations in the SPAST gene causing hereditary spastic paraplegia are related to global topological alterations in brain functional networks. Neurol Sci 40(5):979-984

51. Wang Y, Hao L, Li H, Cleary JD, Tomac MP, Thapa A, Guo X, Zeng D, Wang H, McRae M, Jastrzemski O, Smith-Fassler AM, Xu Y, Xia G (2019) Abnormal nuclear aggregation and myotube degeneration in myotonic dystrophy type 1. Neurol Sci 40(6):12551265

52. Alpaydın Baslo S, Erdoğan M, Balçı ZE, Öztürk O, Ataklı D (2019) Is Hirayama a Gq1b disease? Neurol Sci 40(8):1743-1747

53. Bhoi SK, Jha M, Naik S, Palo GD (2019) Knuckle pigmentation, peripheral neuropathy, madness and abnormal movement: is it B(12) deficiency? Neurol Sci 40(11):2399-2401

54. Pianese L, Fortunato A, Silvestri S, Solano FG, Burlina A, Burlina AP, Ragno M (2019) Maternal germline mosaicism in Fabry disease. Neurol Sci 40(6):1279-1281

55. Sansone VA, Albamonte E, Salmin F, Casiraghi J, Pirola A, Bettinelli M, Rao F, Mancini L, Tovaglieri N, Fedeli F, Stoia P, Heinen M, Cozzi V, Carraro E, Lunetta C, Di Bari A, Mercuri E (2019) Italian EAP working group. Intrathecal nusinersen treatment for SMA in a dedicated neuromuscular clinic: an example of multidisciplinary and integrated care. Neurol Sci 40(2):327-332 
56. Levy M (2019) Ten years of iron chelation in a patient with superficial siderosis. Neurol Sci 40(9):1947-1949

57. Maggi L, Bernasconi P, D'Amico A, Brugnoni R, Fiorillo C, Garibaldi M, Astrea G, Bruno C, Santorelli FM, Liguori R, Antonini G, Evoli A, Bertini E, Rodolico C, Mantegazza R (2019) Italian recommendations for diagnosis and management of congenital myasthenic syndromes. Neurol Sci 40(3):457-468

58. Basantsova NY, Starshinova AA, Dori A, Zinchenko YS, Yablonskiy PK, Shoenfeld Y (2019) Small-fiber neuropathy definition, diagnosis, and treatment. Neurol Sci 40(7):1343-1350

59. Picillo M, Cuoco S, Amboni M, Bonifacio FP, Bruschi F, Carotenuto I, De Micco R, De Rosa A, Del Prete E, Di Biasio F, Elifani F, Erro R, Fabbri M, Falla M, Franco G, Frosini D, Galantucci S, Lazzeri G, Magistrelli L, Malaguti MC, Milner AV, Minafra B, Olivola E, Pilotto A, Rascunà C, Rizzetti MC, Schirinzi T, BorroniB CR, Di Fonzo A, Marchese R, Mercuri NB, Modugno
N, Nicoletti A, Padovani A, Santangelo G, Stefani A, Tessitore A, Volontè MA, Zangaglia R, Zappia M, Zibetti M, Barone P (2019) Validation of the Italian version of the PSP quality of life questionnaire. Neurol Sci 40(12):2587-2594

60. Vita G, Vita GL, Stancanelli C, Gentile L, Russo M, Mazzeo A (2019) Genetic neuromuscular disorders: living the era of a therapeutic revolution. Part 1:peripheral neuropathies. Neurol Sci 40(4): 661-669

61. Vita G, Vita GL, Musumeci O, Rodolico C, Messina S (2019) Genetic neuromuscular disorders: living the era of a therapeutic revolution. Part 2: diseases of motor neuron and skeletal muscle. Neurol Sci 40(4):671-681

Publisher's note Springer Nature remains neutral with regard to jurisdictional claims in published maps and institutional affiliations. 